\title{
Sıcaklığın Terebentin Kompozisyonu Üzerine Etkisi
}

\author{
Ayben KILIÇ-PEKGÖZLÜ* , Esra CEYLAN \\ ${ }^{1}$ Bartın Üniversitesi, Orman Fakültesi, Orman Endüstri Mühendisliği Bölümü, Bartın.
}

\section{Öz}

İğne yapraklı ağaçlarca salgılanan balzam, reçine olarak adlandırılmakta ve \% 20-30'luk kısmını insektisit, dezenfektan, çözücü, parfümeri ve gıda gibi birçok alanda kullanılan terebentin oluşturmaktadır. Bu çalışmada, ticari olarak temin edilen kızılçam reçinesine ait terebentin kompozisyonu üzerine sıcaklığın etkisi incelenmiştir. Kapalı sistemde 2 farklı sıcaklık $\left(85^{\circ} \mathrm{C}-20\right.$ dak. ve $\left.120^{\circ} \mathrm{C}-10 \mathrm{sn}\right)$ uygulanan reçine örneğine ait terebentin hidrodistilasyon yöntemi elde edilmiş ve kromatografik analizlerde kimyasal bileşiminde 46 madde bulunmuştur. Bütün örneklerde $\alpha$-pinen (\% 43,4-48,3) en önemli madde olmuştur. Bu durumu sırası ile $\beta$-pinen $(\% 7,6-8,1), \Delta$-3caren $(\% 6,1-6,7)$ ve longifolen (\% 6,2-8,5) takip etmektedir. Kontrol örneği ile karşılaştırıldığında sıcaklık artışı monoterpen hidrokarbonlarda azalmaya neden olurken, monoterpen-alkol ve seskiterpen hidrokarbonlarda ise artışa neden olmuştur. Ayrıca, sıcaklık uygulama süresi de madde miktarlarındaki değişime etki eden diğer bir faktör olmuştur.

Anahtar Kelimeler: Reçine, Terebentin, Pinus brutia Ten., Monoterpen, Seskiterpen.

\section{Effect of Heat Treatment on the Turpentine Composition}

\begin{abstract}
Resin, secreted from the coniferous tree to protect itself against biotic and abiotic factors, consists of two different fractions as turpentine and rosin. Turpentine, forming 20-30\% of resin, used in different industries such as insecticide, disinfectant, solvent, perfumery and food. In this study, effect of heat treatment on the Pinus brutia turpentine, which was commercially purchased was studied. Two different temperature $\left(85^{\circ} \mathrm{C}-20 \mathrm{~min}\right.$. and $120^{\circ} \mathrm{C}-10 \mathrm{sn}$ ) was applied to resin in a closed system. Turpentine was obtained in a Clevenger and then analysed with GC-FID ve GC-MS. In all samples 46 compound was identified and $\alpha$-pinen (43,4-48,3 \%) was found to be the most abundant compound The other important compounds were $\beta$-pinen $(7,6-8,1 \%), \Delta$-3caren $(6,1-6,7$ $\%)$ and longifolen (6,2-8,5 \%). Heat treatment decreased the amount of monoterpenhydrocarbons compared to control sample. However, monoterpen-alcohol and sesquiterpen hydrocarbons were increased. Treatment time is also another factor effecting the changes.
\end{abstract}

Keywords: Resin, Turpentine, Pinus brutia Ten., Monoterpene, Sesquiterpene. 


\section{Giriş}

Son yıllarda petrol bazlı maddelerden elde edilen ikincil ürünlerin insan sağlığına olan olumsuz etkileri nedeniyle özellikle Avrupa'da yasal bazı kısıtlamalar getirilmiştir. Bu durum biyo bozunur maddelere olan talebin artmasını ve doğal maddelerin tekrar kullanımının yaygınlaşmasını sağlamışıı. Ham reçine bunlardan biri olup, dünyada hızlı büyüyen pazarlar arasında yer almaktadır.

Reçine, TS 4931' e göre oleoresin ya da çam reçinesi olarak tanımlanmış olup, aslında ağacın bir savunma ürünüdür. Özellikle çam türlerinin biotik ve abiotik faktörlere karşı kendini korumak üzere epitel hücrelerde ürettiği ve reçine kanallarında biriktirdiği balzamik salgılardır. Çin, Brezilya ve Endonezya dünyada reçine üretiminin en fazla yapıldığı ülkelerdir. Türkiye'de ise reçine üretimine maliyetler dolayısı ile bir dönem ara vermiş, 2011 yılında Orman Genel Müdürlüğünün yeniden yapılandırılması sonucu, Odun Dışı Ürünler ve Hizmetler Daire Başkanlığı'nın kurulması, 2017-2021 Reçine Eylem Planının hazırlanması ve modifiye kolofan ithal eden firmaların ithalat yerine ülke ormanlarından reçine üretme taleplerinin artması ile son yıllarda ham reçine üretiminde artış görülmektedir (Odabaş Serin vd., 2014; Deniz vd., 2014; Deniz, 2018).

Genel olarak reçine, üretim şartlarına bağlı olarak \% 20-30 terebentin ve \% 70-80 oranında kolofan içermektedir. Terebentin sıvı akışkan kısım olup çoğunlukla monoterpen hidrokarbonlardan ve az miktarda seskiterpenlerden oluşmaktadır. Kolofan ise katı formda olup diterpen hidrokarbonları içermektedir (Güner, 2015; Deniz vd., 2019). Reçine ham olarak tüketilmeyip terebentin ve kolofan olarak fraksiyonlarına ayrıldıktan sonra farklı endüstrilerde değerlendirilmektedir. Kolofan, yaygın olarak kă̆ıt ve boya sanayisinde, matbaa mürekkeplerinde, yapıştırıcılarda, kauçuk ve lastik üretiminde ve yüzey kaplayıcılarında hammadde olarak kullanılmaktadır. Çalışmanın konusunu oluşturan terebentin ise özellikle kimya endüstrisinde çok geniş kullanım alanı bulurken yağlı boya-vernik sanayi, sentetik kauçuk üretimi, seramik endüstrisi, ayakkabı, mobilya ve döşeme cilaları, saf halde antiseptik olarak, kozmetik sanayinde ve insektisitler gibi alanlarda kullanımı ön plana çıkmaktadır (Rodrigues-Correa vd., 2013).

Sıcaklık, nem, 1şık, bakı ve reçine üretim yöntemleri gibi faktörler terebentin ve kolofan verimini etkileyen faktörlerdir. Düşük nem miktarı terebentin kaybına neden olurken sıcaklı̆ı̆ında $40{ }^{\circ} \mathrm{C}$ 'nin üstünde olması önerilmez. Reçine üretimi sırasında uyarıcı kimyasalların kullanımı, ağaç çapı ve güney bakının seçilmesi ise terebentin oranını artırmaktadır.(Aydın, 2017; Odabas-Serin vd., 2017). Reçine eldesinden sonra kullanılacak endüstri alanına göre terebentin ve kolofan ortamdan uzaklaştırılır. Çalışmaya konu olan yem sanayii bu endüstrilerden biridir. İşlemler sırasında uygulanan sıcaklık ve süreye bağlı olarak izomerizasyon, polimerizasyon ve orantısızlık reaksiyonu oluşur. Kolofanda ise dimerizasyon oluşmaktadır ( Takeda vd., 1968; Arkadi vd.,1992)

$\mathrm{Bu}$ çalışmada yem sanayinde katkı maddesi olarak kullanılan kızılçam reçinesine uygulanan farklı sıcaklıkların ve sürenin terebentin miktarı ve içeriğine olan etkisi irdelenmiştir.

\section{Materyal ve Metot}

Çalışma materyali, hayvansal gıda katkı maddesi olarak ham reçine kullanan ticari bir firmadan tedarik edilmiştir. Ham reçine örneklerinin hayvansal gıda katkı maddesi olarak kullanılacak olması nedeniyle herhangi bir kimyasal madde içermemeleri sağlık açısından önem arz etmektedir. Dolayısı ile oyma delik ya da asit-pasta yöntemi gibi kimyasal kullanımı olan reçine elde etme yöntemleri uygulanmamış direk ağaç üzerinden ya da kozalaklarda oluşan ve 1 kış dönemi açık alanda bekletilen reçine örnekleri kullanılmıştır. Elde edilen reçineler analiz sistemlerinde A: Kontrol örneği, B: Kapalı sistemde 20 dakika süre ile $85^{\circ} \mathrm{C}$ sıcaklık uygulanmış reçine ve C: Kapalı sistemde 10 saniye süre ile $120^{\circ} \mathrm{C}$ sıcaklık uygulanmış reçine olmak üzere 3 farklı örnek tipi olarak kullanılmıştır. Clevenger cihazında 3-4 saat hidrodistilasyona tabi tutulmuş ve terebentin-kolofan fraksiyonları birbirinden ayrılmıştır. Deneyler sırasında $20 \mathrm{~g}$ ham reçine kullanılmış ve 2 tekrarlı hidrodistilasyon yapılmıştır. Terebetin örnekleri amber renkli şişelere alınmış ve kalitatif-kantitatif analizlere kadar +4 derecede bekletilmiştir.

Kalitatif analizler, Shimadzu GCMS-QP2010 marka GC-MS cihazında TRB-5MS tipi kolon kullanılarak gerçekleştirilmiştir. Kolon uzunluğu $30 \mathrm{~m}$, kalınlığ $0,25 \mu \mathrm{m}$ ve çap $10,25 \mathrm{~mm}$ 'dir. Örnekler 1:50 oranında dietileter ile seyreltildikten sonra $50^{\circ} \mathrm{C}$ başlangıç sıcaklığı ve dakikada $4{ }^{\circ} \mathrm{C}$ artışla $260^{\circ} \mathrm{C}$ son sıcaklıkta 10 dakika bekleyen bir sıcaklık programı uygulanmıştır. Taşıcıyı gaz olarak helyum kullanılmıştır. Maddelerin tanımlanmasında FFSC, NIST ve WILEY kütüphanelerinden yararlanılmıştır. Split:1:25 uygulanmıştır. 
Kantitatif analizler ise Shimadzu GC-2010 marka GC-FID cihazında TRB-5 tipi kolon kullanılarak gerçekleştirilmiştir. Kantitatif analizlerde kullanılan GC-FID cihazı sıcaklık programı kalitatif analizlerde kullanılan sıcaklık programıyla aynı şartlardadır. Taşıcı gaz olarak hidrojen kullanılmıştır. Tespit edilecek maddelerin kovats indeks değerlerinin (RI) hesaplanmasında Supelco C7-C30 alkan karışımı kullanılmıştır. Her bir deney örneği 3 tekrarlı enjekte edilmiştir.

\section{Bulgular ve Tartışma}

Hidrodistilasyon sonrası elde edilen terebentin fraksiyonlarına ait miktarlar Tablo 1'de verilmiştir. Genel olarak terebentin miktarlarının \% 3 civarında olduğu görülmektedir. Sıcaklık uygulanmış ve uygulanmamış örnekler arasında terebentin miktarı açısından belirgin bir fark görülmemiştir. Bu durum, uygulanan sıcaklık değerlerinin $150^{\circ} \mathrm{C}^{\prime}$ yi geçmemesinden kaynaklanmıştır. Terebentine ait kaynama noktası $150^{\circ} \mathrm{C}$ 'nin üzerindedir. Terebentini oluşturan $\alpha$-pinen $154-159^{\circ} \mathrm{C}$ ve $\beta$-pinen $156-166^{\circ} \mathrm{C}$ kaynamaktadır.

Tablo 1. Farklı sıcaklıklar uygulanmış kızılçam ham reçinesine ait terebentin miktarları (\%)

\begin{tabular}{|c|c|c|}
\hline Örnek No & $\begin{array}{c}\text { Terebentin } \\
\text { Miktarı } \\
\end{array}$ & $\begin{array}{c}\text { OrtalamaDeğer/ } \\
\text { Std.sapma }\end{array}$ \\
\hline A1 (kontrol) & 3,44 & \multirow{2}{*}{$3,22 \pm 0,3$} \\
\hline A2 (kontrol) & 3,01 & \\
\hline $\mathrm{B} 1$ (85 ${ }^{\circ} \mathrm{C}-20$ dak.) & 3,44 & \multirow{2}{*}{$3,44 \pm 0,0$} \\
\hline B2 (85 ${ }^{\circ} \mathrm{C}-20$ dak.) & 3,44 & \\
\hline $\mathrm{C} 1\left(120^{\circ} \mathrm{C}-10 \mathrm{sn}\right)$ & 3,01 & \multirow{2}{*}{$3,02 \pm 0,01$} \\
\hline $\mathrm{C} 2\left(120^{\circ} \mathrm{C}-10 \mathrm{sn}\right)$ & 3,03 & \\
\hline
\end{tabular}

Frances vd., (2020) tarafından sahilçamı reçinesi ile yapılan çalışmada üç farklı $\left(180,200,250{ }^{\circ} \mathrm{C}\right)$ sicaklık uygulamış ve kalıntı terebentin miktarının $180^{\circ} \mathrm{C}$ 'nin üzerinde arttığı ancak $200^{\circ} \mathrm{C}$ ve $250^{\circ} \mathrm{C}$ 'lerde farkın çok az olduğu ifade edilmiştir.

Materyal kısmında bahsedildiği gibi örnekler 1 yıl kar üzerinde beklediğinden, terebentin oranı diğer yöntemlere göre daha düşük bulunmuştur. Aydın, 2017'de oyma delik ve asit-pasta yöntemleri ile kızılçamdan reçine elde etmiş ve bu reçinenin terebentin oranını \% 25-30 arasında tespit etmiştir. Bu çalışmada, kullanılan kızılçam reçinesine benzer şekilde geleneksel olarak elde edilen Toros Göknarı reçinesi ( Abies cilicica) ile yapılan çalışmada ise terebentin oranı \% 14,3 olarak tespit edilmiştir (Pekgözlü Kilic ve Güner, 2018).

Elde edilen terebentinler içerik analizler için GC-FID ve GC-MS'de analiz edilmiştir (Şekil 1). Sonuçlar Tablo 2' de verilmiş ve her üç örnekte'de toplam 46 maddenin tespit edildiği, bunlardan 38 tanesinin monoterpen, 8 maddenin ise seskiterpen hidrokarbon olduğu görülmektedir.

Tanımlanan bileşikler içerisinde $\alpha$-pinen (\% 43,4-48,3) en yüksek miktarları veren monoterpen olmuştur. Bu maddeyi sırasıyla $\beta$-pinen, $\Delta$-3-karen ve d-limonen takip etmektedir. Seskiterpenler içinde ise $\alpha$-longifolen en önemli bileşik olarak tespit edilmiştir. Diğer seskiterpenler \% 1 'in altında olarak hesaplanmıştır. Tanımlanan içerik literatür çalışmalarıyla benzerlik göstermektedir. Acar (1983), tarafindan yapılan çalışmada kızılçam terebentininde 13 madde tanımlanmıştır. $\alpha$-pinen oranı ortalama \% 77,5 ve $\beta$-pinen \% 12,6 bulunmuştur. Bir başka çalışmada asit pasta yöntemi ve reçine kelebeği (Dioryctria sylvestrella Ratz.) tarafından açılan galerilerden toplanan kızılçam reçinesine ait terebentin analizlerine önemli bileşikler yine sırasıyla $\alpha$-pinen (\% 19,7 ve \% 20) ve $\beta$-pinen (\% 13,3 ve \% 9,4) olarak tespit edilmiştir (Öz vd., 2015). Odabas-Serin vd., (2018) tarafından yapılan çalışmada oyma delik yöntemi ile kızılçamdan elde edilen terebentine ait içerikte $\alpha$-pinen \% 60,5, $\Delta$-3-karen \% 17,2 ve $\beta$-pinen \% 12,4 olarak tespit edilmiştir. 
Tablo 2. Farklı sıcaklıklarda muamele edilmiş kızılçam terebentine ait kimyasal kompozisyon (\%).

\begin{tabular}{|c|c|c|c|c|c|}
\hline No & RI & Bileşik & $\begin{array}{l}\text { Kontrol } \\
\text { (Örnek A) }\end{array}$ & $\begin{array}{l}85^{\circ} \mathrm{C}-20 \text { dak. } \\
\text { (Örnek B) }\end{array}$ & $\begin{array}{l}120^{\circ} \mathrm{C}-10 \text { sn } \\
(\text { Örnek C) }\end{array}$ \\
\hline 1 & 921 & tricylene & $0,16 \pm 0,01$ & $0,15 \pm 0,01$ & $0,15 \pm 0,01$ \\
\hline 2 & 925 & $\alpha$-thujen & $0,02 \pm 0,01$ & $0,02 \pm 0,01$ & $0,03 \pm 0,01$ \\
\hline 3 & 934 & $\alpha$-pinen & $48,3 \pm 2,2$ & $43,4 \pm 1,0$ & $45,3 \pm 0,3$ \\
\hline 4 & 947 & $\alpha$-fenchen+camphene & $4,34 \pm 0,1$ & $4,27 \pm 0,1$ & $4,22 \pm 0,0$ \\
\hline 5 & 952 & 2,4(10)-thujadiene & $1,33 \pm 0,01$ & $1,36 \pm 0,01$ & $1,31 \pm 0,01$ \\
\hline 6 & 969 & sabinen & $0,97 \pm 0,01$ & $0,92 \pm 0,01$ & $0,96 \pm 0,01$ \\
\hline 7 & 976 & $\beta$-pinene & $8,12 \pm 0,2$ & $7,63 \pm 0,0$ & $8,00 \pm 0,0$ \\
\hline 8 & 990 & $\beta$-myrcene & $0,11 \pm 0,01$ & $0,08 \pm 0,01$ & $0,10 \pm 0,01$ \\
\hline 9 & 991 & 1,5,8-p-menthatriene & $0,16 \pm 0,01$ & $0,19 \pm 0,01$ & $0,17 \pm 0,01$ \\
\hline 10 & 1004 & $\alpha$-phellandrene & $0,27 \pm 0,01$ & $0,26 \pm 0,01$ & $0,23 \pm 0,01$ \\
\hline 11 & 1010 & $\Delta$-3-caren & $6,73 \pm 0,2$ & $6,06 \pm 0,0$ & $6,47 \pm 0,0$ \\
\hline 12 & 1016 & $\alpha$-terpinen & $0,14 \pm 0,01$ & $0,12 \pm 0,01$ & $0,13 \pm 0,01$ \\
\hline 13 & 1021 & p-cymene & $0,20 \pm 0,01$ & $0,20 \pm 0,01$ & $0,21 \pm 0,01$ \\
\hline 14 & 1023 & o-cymene & $1,47 \pm 0,01$ & $1,49 \pm 0,01$ & $1,51 \pm 0,01$ \\
\hline 15 & 1027 & d-Limonene & $3,19 \pm 0,1$ & $2,93 \pm 0,01$ & $3,09 \pm 0,1$ \\
\hline 16 & 1057 & $\gamma$-terpinene & $0,22 \pm 0,02$ & $0,21 \pm 0,01$ & $0,19 \pm 0,01$ \\
\hline 17 & 1082 & m-cymenene & $0,27 \pm 0,01$ & $0,32 \pm 0,01$ & $0,28 \pm 0,01$ \\
\hline 18 & 1089 & p-cymenene & $1,54 \pm 0,01$ & $1,66 \pm 0,01$ & $1,53 \pm 0,01$ \\
\hline 19 & 1113 & $\alpha$-fenchol & $0,68 \pm 0,1$ & $0,82 \pm 0,01$ & $0,77 \pm 0,01$ \\
\hline 20 & 1125 & $\alpha$-campholene aldehyde & $0,63 \pm 0,01$ & $0,75 \pm 0,02$ & $0,69 \pm 0,01$ \\
\hline 21 & 1139 & trans-pinocarveol & $2,24 \pm 0,2$ & $2,78 \pm 0,1$ & $2,53 \pm 0,01$ \\
\hline 22 & 1144 & camphor & $0,25 \pm 0,02$ & $0,32 \pm 0,02$ & $0,26 \pm 0,01$ \\
\hline 23 & 1148 & exo-methyl-camphenilol & $0,40 \pm 0,01$ & $0,48 \pm 0,01$ & $0,45 \pm 0,01$ \\
\hline 24 & 1156 & isoborneol & $0,15 \pm 0,01$ & $0,20 \pm 0,02$ & $0,19 \pm 0,01$ \\
\hline 25 & 1160 & trans-3-pinanone & $0,40 \pm 0,01$ & $0,48 \pm 0,01$ & $0,45 \pm 0,01$ \\
\hline 26 & 1162 & pinocarvone & $0,42 \pm 0,01$ & $0,52 \pm 0,01$ & $0,46 \pm 0,01$ \\
\hline 27 & 1166 & borneol & $1,53 \pm 0,2$ & $1,90 \pm 0,1$ & $1,68 \pm 0,01$ \\
\hline 28 & 1177 & terpinen-4-ol & $0,60 \pm 0,1$ & $0,68 \pm 0,0$ & $0,66 \pm 0,01$ \\
\hline 29 & 1182 & cumyl alcohol & $0,64 \pm 0,1$ & $0,80 \pm 0,1$ & $0,73 \pm 0,01$ \\
\hline 30 & 1186 & p-cymen-8-ol & $0,62 \pm 0,2$ & $0,81 \pm 0,01$ & $0,72 \pm 0,01$ \\
\hline 31 & 1191 & $\alpha$-terpineol & $1,59 \pm 0,2$ & $1,90 \pm 0,1$ & $1,70 \pm 0,01$ \\
\hline 32 & 1197 & Myrtenol & $1,82 \pm 0,2$ & $2,26 \pm 0,1$ & $2,02 \pm 0,01$ \\
\hline 33 & 1210 & Verbenone & $1,12 \pm 0,02$ & $1,49 \pm 0,01$ & $1,37 \pm 01$ \\
\hline 34 & 1219 & trans-carveol & $0,30 \pm 0,02$ & $0,38 \pm 0,01$ & $0,35 \pm 0,01$ \\
\hline 35 & 1228 & Bornyl acetat & $0,12 \pm 0,01$ & $0,16 \pm 0,01$ & $0,14 \pm 0,01$ \\
\hline 36 & 1231 & cis-carveol & $0,07 \pm 0,01$ & $0,09 \pm 0,01$ & $0,16 \pm 0,01$ \\
\hline 37 & 1240 & myrtenyl acetat & $0,25 \pm 0,01$ & $0,33 \pm 0,01$ & $0,15 \pm 0,01$ \\
\hline 38 & 1244 & carvone & $0,12 \pm 0,1$ & $0,16 \pm 0,01$ & $0,15 \pm 0,01$ \\
\hline 39 & 1351 & $\alpha$-Longipinene & $0,46 \pm 0,01$ & $0,61 \pm 0,01$ & $0,57 \pm 0,01$ \\
\hline 40 & 1368 & cyclosativen & $0,07 \pm 0,1$ & $0,09 \pm 0,01$ & $0,08 \pm 0,01$ \\
\hline 41 & 1371 & Longicyclene & $0,39 \pm 0,01$ & $0,52 \pm 0,01$ & $0,48 \pm 0,01$ \\
\hline 42 & 1376 & $\alpha$-ylangene & $0,06 \pm 0,01$ & $0,08 \pm 0,01$ & $0,07 \pm 0,01$ \\
\hline 43 & 1391 & sativen & $0,12 \pm 0,01$ & $0,16 \pm 0,3$ & $0,15 \pm 0,01$ \\
\hline 44 & 1408 & $\alpha$-longifolen & $6,24 \pm 0,9$ & $8,51 \pm 0,01$ & $7,82 \pm 0,01$ \\
\hline 45 & 1421 & caryophllene & $0,98 \pm 0,1$ & $1,25 \pm 0,01$ & $1,18 \pm 0,01$ \\
\hline 46 & 1455 & $\alpha$-humulen & $0,18 \pm 0,01$ & $0,23 \pm 0,01$ & $0,21 \pm 0,01$ \\
\hline
\end{tabular}


Örnek A

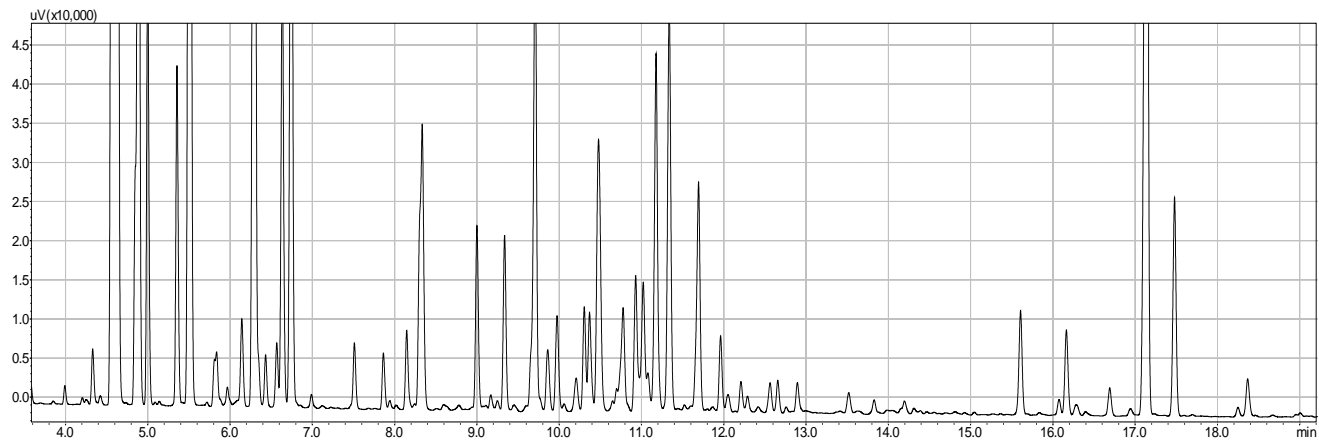

Örnek B

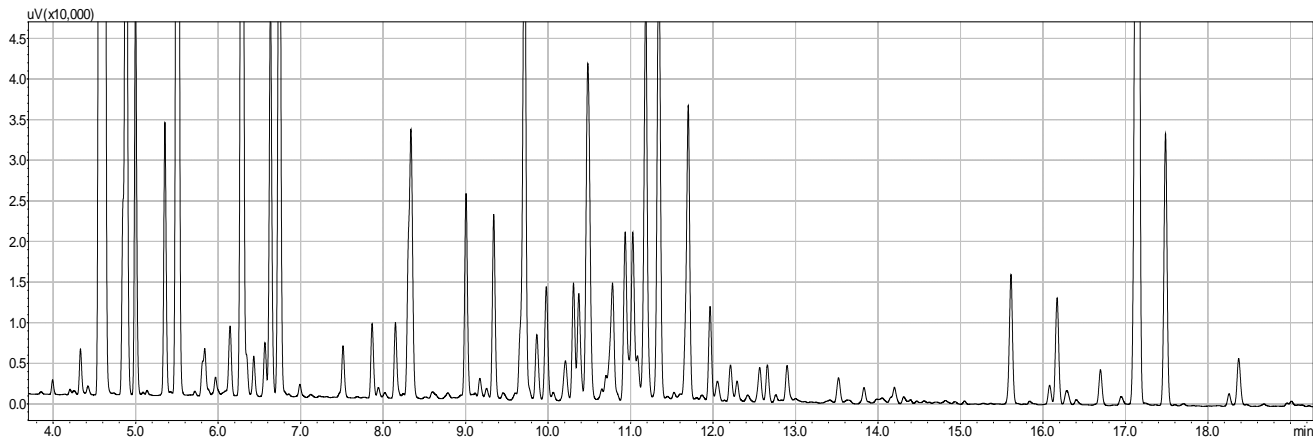

Örnek C

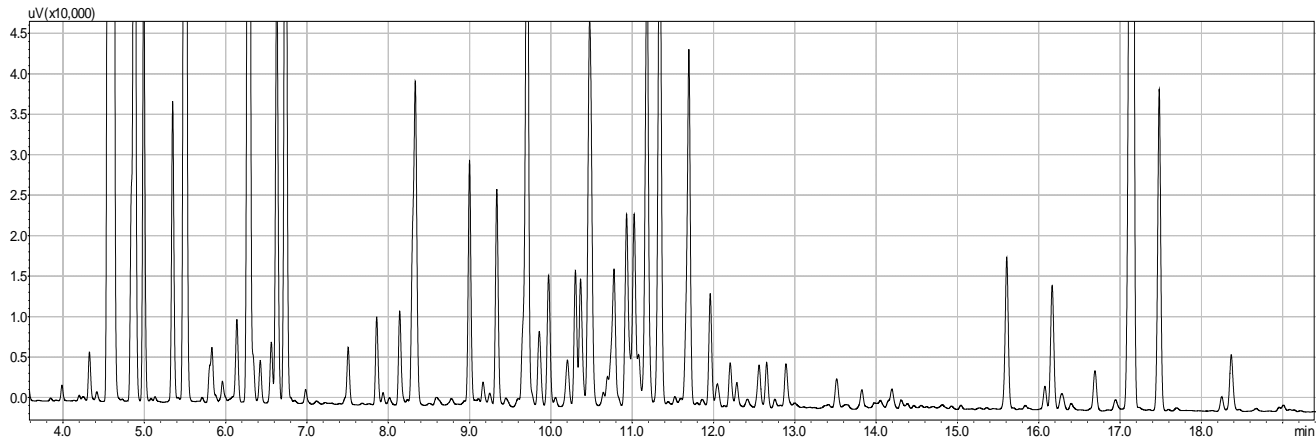

Şekil 1. Farklı sıcaklıklarda muamele edilmiş Kızılçam terebentine ait GC-FID kromatogramları.

Çalışmada kullanılan ham reçine örneklerine kapalı sistemde uygulanan sıcaklığın özellikle monoterpenlerin miktarında azalmaya sebep olduğu gözlenmiştir. Hiçbir sıcaklık uygulanmayan kontrol örneğinde \% 48,3 olan $\alpha$ pinen miktarı sıcaklı̆̆ın $85^{\circ} \mathrm{C}$ çıkmasıyla \% 5 oranında azalmıştır. C örneğinde ise sıcaklığın artışı azalmaya neden olsa da sürenin kısa olması (10 saniye) $\alpha$-pinen miktarındaki azalışı sadece \% 3 oranında etkilemiştir (Şekil 2). Sıcaklık ve muamele süresi terebentin içeriklerini etkilemektedir. Benzer azalmalar farklı oranlarda da olsa diğer monoterpenler de de tespit edilmiştir. Ticari olarak terebentinin uzaklaştırılmasında $165{ }^{\circ} \mathrm{C}$ sıcaklık kullanılmaktadır (Takeda vd., 1968). 


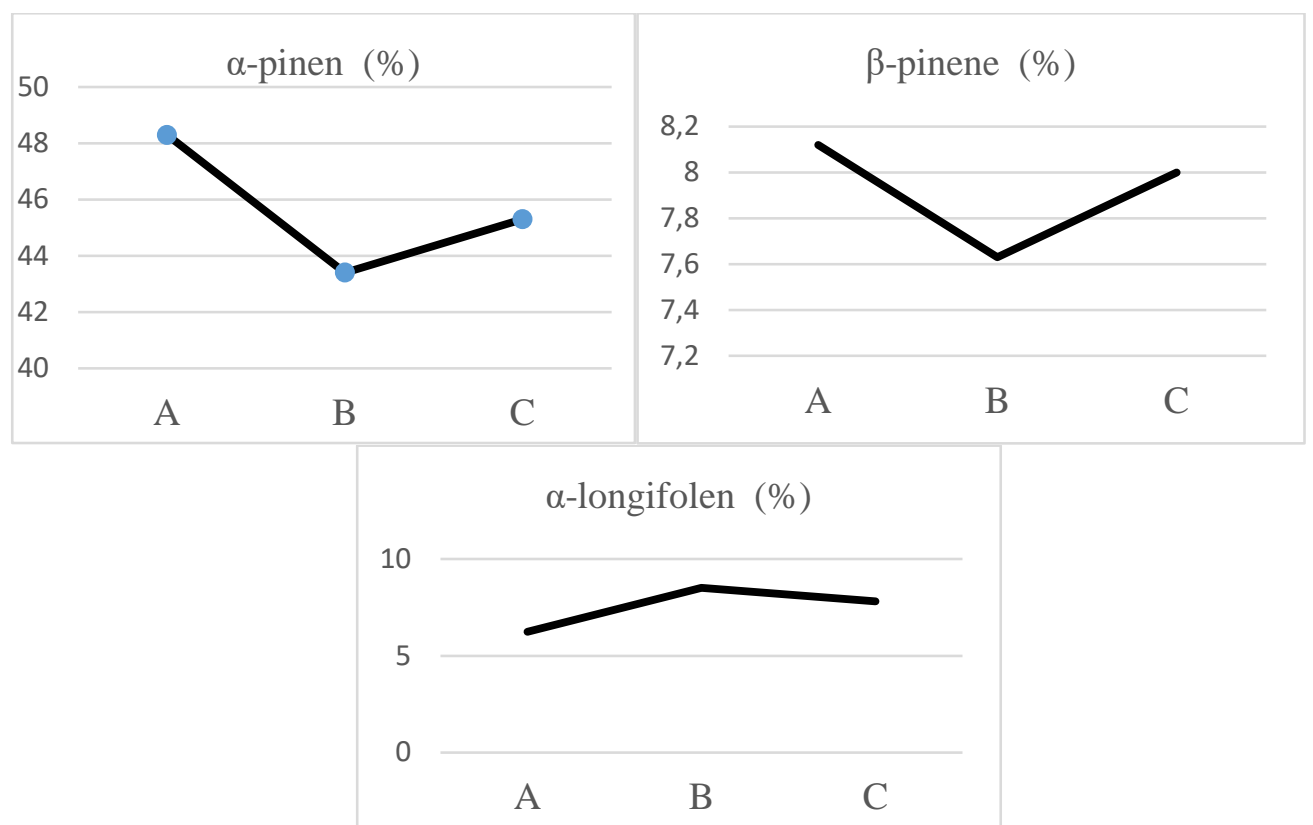

Şekil 2. Farklı sıcaklıklar uygulanmış kızılçam ham reçinesine ait değişimler (A:kontrol, B: $85^{\circ} \mathrm{C}$ sıcaklık uygulanmış, C: $120^{\circ} \mathrm{C}$ sıcaklık uygulanmış örnek)

Bilindiği gibi verbenone maddesi $\alpha$-pinen'in oksidasyonu ile edilmektedir. Bu durum çalışma sonuçlarında da görülmektedir. Kontrol örneğinde $\alpha$-pinen \% 48,3 iken verbenone \% 1,12, B örneğinde $\alpha$-pinen \% 43,4 iken 1,49 olmuştur. Diğer bir dönüşümde, $\alpha$-terpinen’de görülmektedir. Bu madde sıcaklığın etkisi ile $\alpha$-terpineol, terpinen4-ol, linalool oxide gibi maddelere dönüşmektedir (Varming vd., 2006). Reçine ile yapılan bu çalışmada da $\alpha$ terpinen'in azalması ile $\alpha$-terpineol ve terpinen-4-ol maddelerinde artışlar belirlenmiştir.

Seskiterpen grubunda ise tersi bir durum görülmektedir (Şekil 2). Sıcaklık artışı madde miktarında artış sağlamıştır. En önemli seskiterpen hidrokarbon olan $\alpha$-longifolen kontrol örneğinde \% 6 civarında bulunurken, B örneğinde bu oran \% 8,5 ve C örneğinde \% 7,8 olarak tespit edilmiştir. Caryophllene ve longicyclene gibi diğer seskiterpenlerde de benzer artışlar gözlenmiştir.

\section{Sonuç ve Öneriler}

Terebentin içeriğinin yaklaşık \% 50'sinden fazlasını oluşturan $\alpha$-pinen ve $\beta$-pinen maddeleri gıda, parfümeri ve kozmetik endüstrilerinde yaygın olarak kullanılmaktadır. Diğer bir kullanım alanı da antioksidan özelliği ile ilaç sanayisidir (Rodrigues-Correa vd., 2013). Kızılçam reçinesi, bu bilimsel verilerin yanı sıra geleneksel olarak Kaz dağlarında yerel halk tarafından ağız ve diş temizliği, öksürük giderici, şeker hastalığı, mide ülserinde ve yara iyileştirici olarak da kullanılmaktadır (Satil vd., 2011).

Bu çalışmada kapalı sistem içerisinde sıcaklık uygulanan oksitlenmiş kızılçam reçinesine ait terebentin içerikleri incelenmiştir. Tüm örneklerde $\alpha$-pinen en önemli madde olarak tespit edilmiştir. Bu maddeyi sırasıyla $\beta$-pinen, $\Delta$ 3-caren, d-limonen ve $\alpha$-longifolen izlemektedir. Kontrol örneği ile yapılan karşılaştırmada sıcaklığın özellikle monoterpen hidrokarbonların miktarını azalttığı, buna karşılık monoterpen-alkol ve seskiterpen hidrokarbonların miktarında benzer şekilde artışlara neden olduğu belirlenmiştir. Sıcaklığın yanı sıra muamele süreside bu değişimlerde etkili olan diğer bir faktör olmuştur.

\section{Kaynaklar}

1. Acar, İ. (1983). Kızılçam, karaçam, Fıstıkçamı reçinelerinin terebentin ve kolofan analizleri. İ.Ü Orman Fakültesi dergisi, Cilt:34, Say1:1.

2. Artaki, I., Ray, U., Gordon, H.M., Gervasio, M.S. (1992). Thermal degradation of rosin during high temperature solder reflow. Thermochimica Acta, 198,7-20.

3. Aydın, İ. (2017). Türkiye'de Sahilçamı ve Kızılçamdan asit pasta ve oyma delik yöntemleri ile reçine üretimi ve terebentin analizi. KTÜ, Fen Bilimleri, Orman Endüstri Müh. A.B.D. Trabzon. 
4. Deniz, İ., Odabaş-Serin, Z., Öz, M., Okan, O. T., Yılmaz, B., Pekel, M. (2014). Ülkemizde asit-pasta yöntemi ile reçine (oleoresin) üretimi çalışmaları, III. Uluslararası Odun Dışı Orman Ürünleri Sempozyumu, 8-10 Mayıs, Kahramanmaraş, Türkiye.

5. Deniz, İ. (2018). Odun Dışı Orman Ürünleri Endüstrisi, Ders notu, KTÜ, Orman Fakültesi, Orman End. Müh. Böl. 203s.

6. Deniz, İ., Pekgözlü, A., Dönmez, İ. E., Karaoğul, E., Yılmaz, B., Ceylan, E., Aydın, İ. (2019). Ülkemizde üretilen kolofanların kimyasal özellikleri, I. Kolofan ve Türevleri Çalıştayı, 2 Mayıs 2019, İCÜ Orman Fakültesi.

7. Frances, M., Gardere, Y., Rubini, M., Duret, E., Leroyer, E., Cabaret, T., Bikoro Bi Athomo, A., Charrier, B. (2020). Effect of heat treatment on Pinus pinaster rosin: A study of physico chemical changes and influence on the quality of rosin linseed oil varnish. Industrial Crops \& Products 155, 112789.

8. Güner, E. (2015).Toros Göknarı Reçinesinin Kimyasal Analizi, Yüksek lisans tezi, Bartın Üniversitesi, Fen Bilimleri, Orman Endüstri Müh. A.B.D.,Bartın.

9. Odabaş-Serin, Z., Deniz, İ., Kılıç, M. (2014). Reçinenin Önemi, Türkiye ve Dünyadaki durumu. III. Uluslararası Odun dışı orman ürünleri sempozyumu, 8-10 Mayıs, pp.584-592, Kahramanmaraş.

10. Odabaş-Serin, Z., Ünaldı, E., Çiçekler, M. (2017). Oleoresin yield of Pinus Brutia Ten. in Turkey; Effect of tree diameter, type of stimultant chemicals and concentration rate, IV. International Multidisciplinary Eurasian Congress (IMCOFE 2017), 23- 25 August 2017, Rome-Italy, Vol. 3, 223-227.

11. Odabaş-Serin, Z,. Kılıç-Pekgözlü, A., Ünaldı, E. (2018). Chemical Composition of Pinus brutia Ten. Turpentine, Proceedings of the International Forest Products Congress, Trabzon, Turkey, 26-29 September 2018, 318-321, ORENKO 2018 Paper ID.63, 328-332

12. Öz, M., Deniz, İ., Okan, O. T., Fidan, M. S. (2015). Chemical composition of oleoresin and larvea gallery resin of pinus brutia attacked by Dioryctria Sylvestrella Ratz. Drvna Industrija 66(3) 179-188.

13. Pekgözlü-Kilic, A., Ceylan, E. (2018). Chemical composition of taurus fir (Abies cilicica subsp. isaurica) Oleoresin” Revista Árvore. 42(1):e420115

14. Rodrigues-Correa, K. C. S., Lima, J. C., Fett-Neto, A. G. (2013). Oleoresins from Pine: production and Industrial Uses. Natural Products. Springer-Verlag Berlin.

15. Satil, F., Selvi, S., Polat, R. (2011). Ethic usage of pine resin production from P.brutia by native people on the Kazdağ mountain in Western Turkey. Journal of Food, Agriculture \& Enviroment 9(3\&4) 1059-1063.2

16. Takeda, H., Kanno, H., Schuller, W., Lawrence, R. (1968). Effect of Temperature on Rosins and Pine Gum. L\&Ec Product Research and Development. Vol. 7 No. 3 September.

17. Varming, C., Andersen, M., Poll, L. (2006). Volatile monoterpenes in Black Currant Juice: Effects of heating and enzymatic treatment by b-Glucosidase. J.agric.Food Chem. 54 2298-2302. 